\title{
Article
}

\section{HRI Malta 2017-Cutting Edge Research in Homeopathy: HRI's Third International Research Conference in Malta}

Mosley, Angelina, Partington, Hazel, Gaertner, Katharina, Fisher, Peter, Rutten, A. L. B., Mathie, Robert, Cartwright, Steven, Fixsen, Alison, Kokornaczyk, Maria, Sokol, Anezka, Tournier, Alexander and Roberts, E.

Available at http://clok.uclan.ac.uk/21560/

Mosley, Angelina, Partington, Hazel ORCID: 0000-0003-3566-7035, Gaertner, Katharina, Fisher, Peter, Rutten, A. L. B., Mathie, Robert, Cartwright, Steven, Fixsen, Alison, Kokornaczyk, Maria et al (2017) HRI Malta 2017-Cutting Edge Research in Homeopathy: HRI's Third International Research Conference in Malta. Homeopathy, 107 (01). 050-054. ISSN 1475-4916

It is advisable to refer to the publisher's version if you intend to cite from the work. http://dx.doi.org/10.1055/s-0037-1609018

For more information about UCLan's research in this area go to http://www.uclan.ac.uk/researchgroups/ and search for <name of research Group>.

For information about Research generally at UCLan please go to http://www.uclan.ac.uk/research/

All outputs in CLoK are protected by Intellectual Property Rights law, including Copyright law. Copyright, IPR and Moral Rights for the works on this site are retained by the individual authors and/or other copyright owners. Terms and conditions for use of this material are defined in the policies page. 


\title{
CONFERENCE REPORT
}

\section{HRI Malta 2017 - Cutting Edge Research in Homeopathy: HRI's third international research conference in Malta}

\author{
Angelina J Mosley ${ }^{1}$, E Rachel Roberts ${ }^{1, *}$, Hazel Partington ${ }^{2}$, Katharina Gaertner ${ }^{3}$, Peter \\ Fisher $^{4}$, Lex ALB Rutten ${ }^{5}$, Robert T Mathie ${ }^{1}$, Steven J Cartwright ${ }^{6}$, Alison Fixsen ${ }^{7}$, Maria \\ Olga Kokornaczyk ${ }^{8}$, Anezka Marie Sokol ${ }^{9}$, Alexander L Tournier ${ }^{1}$ \\ ${ }^{1}$ Homeopathy Research Institute, London, UK \\ 2University of Central Lancashire, UK \\ ${ }^{3}$ Institute for Complementary Medicine, University of Bern, Switzerland \\ ${ }^{4}$ Royal London Hospital for Integrated Medicine, London, UK \\ 5 Independent researcher, Netherlands \\ ${ }^{6}$ Cherwell Innovation Centre, Oxford, UK \\ 7 University of Westminster, London, UK \\ ${ }^{8}$ Society for Cancer Research, Switzerland \\ ${ }^{9}$ Institute of Integrative Medicine, University of Witten-Herdecke, Germany
}

*Correspondence: E Rachel Roberts, Homeopathy Research Institute, International House, 124 Cromwell Road, London SW7 4ET, UK

E-mail: rachelroberts@hri-research.org

\section{Abstract}

The $3^{\text {rd }}$ international conference on 'Cutting Edge Research in Homeopathy' organised by the Homeopathy Research Institute (HRI) was held on the inspiring and historic island of Malta from $9^{\text {th }}-11^{\text {th }}$ of June, 2017.

102 abstracts underwent peer review by the HRI Scientific Advisory Committee and external experts to produce the programme of 36 oral presentations and 37 posters, presented by researchers from 19 countries. The two and a half day programme covered a diverse range of topics including quantitative and qualitative clinical research, basic research, veterinary research and provings. These intensive plenary and parallel sessions were interspersed with multiple opportunities for delegates to discuss and exchange ideas, in particular through interactive panel discussions and a pre-conference workshop.

The continuing commitment of the homeopathy research community to generating high quality studies in this rapidly evolving field was clear. In this conference report we present highlights from this memorable event.

\section{Keywords}

Homeopathy research; Systematic review; antimicrobial resistance; Conference; HRI;

Clinical trials; Fundamental research 


\section{Providing a platform for global research}

Following previous conferences in Barcelona (2013) and Rome (2015), the HRI was proud to once again host a world-class event in the homeopathy calendar dedicated to 'Cutting Edge Research in Homeopathy', this time on the island of Malta. As homeopathy continues to face significant challenges in many parts of the world, research is playing an ever more vital role in the development of homeopathy as an academic field and medical discipline. Within this intense international debate HRI Malta 2017 provided a platform for showcasing the latest findings from the global homeopathic research community.

\section{The clinical benefits of an integrated approach}

HRI Malta 2017 was opened by Prof Angela Xuereb, Dean of Health Sciences and Head of Applied Biomedical Sciences at the University of Malta. Prof Xuereb reminded the audience that the University of Malta is one of the oldest medical schools in the world and provides training across different medical disciplines "for the good of the patient", with collaboration as a key guiding principle.

The benefits of constructive dialogue between different medical disciplines, including homeopathy, were further emphasised by our keynote speakers. Prof Michael Frass (Germany) and Dr Elio Rossi (Italy), both presented data on the positive role that adjunctive homeopathic treatment can play in cancer patients. Drawing on his extensive experience, Prof Frass called for an increased use of homeopathy alongside conventional care for patients with cancer, listing a wide scope of potential applications. For Prof Frass, the most important of these is the enhancement of patients' quality of life ${ }^{1}$, which was also echoed by Dr Rossi's presentation based on his work in Lucca, Italy. Dr Emma Macías-Cortés (Mexico) presented her keynote address describing a high quality double-blind, double-dummy superiority trial, comparing three test groups receiving homeopathy or fluoxetine or placebo; this study demonstrated the clinical benefits of individualised homeopathy for peri- and postmenopausal women with depression².

Taken together, these three key presentations highlighted what can be achieved when homeopathy is integrated into conventional healthcare.

\section{Antimicrobial Resistance}

New for HRI Malta 2017 were two interactive panel discussion sessions to further promote the exchange of ideas.

The first session tackled Homeopathy and Antimicrobial Resistance (AMR) - a topic recently announced by the World Health Organization (WHO) as one of the main future challenges in public health. To set the scene, Dr Peter Fisher's (UK) presentation emphasised the impact of AMR on both human health and the spiralling costs of conventional healthcare; Dr. Alison Fixsen (UK) discussed the evidence of homeopathic interventions in upper respiratory tract infections and Petra Klement (Germany) further supported this point, presenting the results of a new placebo-controlled trial showing that the homeopathic complex Tonsilotren decreased infection rates in patients with recurrent tonsillitis.

The subsequent panel discussion focused on the problem that despite encouraging results, complementary treatment approaches are still not part of the available treatment guidelines 
for infectious diseases or the global WHO strategy for tackling antimicrobial resistance ${ }^{3}$. This raised the important question of how we can implement and encourage the inclusion of homeopathy as a viable contributor to tackling this global problem.

\section{Systematic reviews of published literature}

As highlighted by the presentations on AMR, analysing the published scientific literature is essential for informing future research and clinical guidelines, especially when done using the most rigorous methods. Dr Robert Mathie (UK) gave two presentations reporting on his programme of systematic reviews. His review of pragmatic trials comparing homeopathy with 'other than placebo' controls identified trials using 'add-on homeopathy' as the most promising area for future research. His review of double-blind, placebo-controlled randomised trials of non-individualised homeopathic treatment found that including model validity in assessment of trial "reliability" had an important impact on the results ${ }^{4}$.

Dr Katharina Gaertner (Switzerland) presented a systematic review of clinical trials including observational studies - an innovative approach as these studies are usually dismissed as being lower on the hierarchy of evidence.

In stark contrast, Rachel Roberts (UK) presented an in-depth analysis and critique of the Australian National Health and Medical Research Council's report on homeopathy. Roberts revealed multiple methodological flaws in the 'Australian Report' and concluded that these errors constitute a case of misfeasance, not unintentional scientific error ${ }^{5}$.

\section{Latest clinical research findings}

Three clinical research sessions included recent studies on a wide range of clinical conditions. Presentations were given on aggravations after homeopathic treatment in chronic conditions (Eizayaga, Argentina), a pilot feasibility study in homeopathy versus usual care for attention deficit and hyperactivity disorder (Fibert, UK), the challenges of performing an international pilot clinical trial in pre-menstrual syndrome (Klein-Laansma, Netherlands), management of recurrent respiratory tract infections with Emtact30 (Shah, India) and the potential role of individualised homeopathic treatment as an adjunct in type II diabetic patients with poor glycaemic control (To, Hong Kong $)^{6}$.

\section{Learning from 'failed' studies}

Two further keynote presentations were given by Dr Stephan Baumgartner (Germany) and Prof Harald Walach (Germany) who both looked back over two decades of research in their respective fields, with the ultimate aim of framing our next steps for future research.

Dr Baumgartner presented an overview of key experimental models that have demonstrated reproducible and reliable differences between ultra-high dilutions and controls. Dr Baumgartner also unpicked many problems he faced when performing in vitro and in vivo basic experiments on ultra-high dilutions. He stressed that we should not be deterred when experiments 'don't work'; rather, a deeper understanding of the experimental system often reveals the subtle parameters which lead to success or failure of the experiments. For example, when we take a broader look at the results of basic research, patterns emerge, such as the cyclical response to remedies as a function of varying potency, which $\mathrm{Dr}$ Baumgartner proposes we call 'Kolisko-Steiner Patterns'. 
In the closing keynote address, Prof Walach delivered a thought-provoking presentation on the issue of non-reproducibility in provings using a double blind trial design ${ }^{7}$. Prof Walach postulated that the experiences of provers were non-local rendering traditional experimental methods problematic. Thus, Prof Walach challenged us to consider that the design of any experiment, proving or clinical test automatically creates underlying assumptions about the direction of cause and effect of remedies ${ }^{8}$.

\section{Addressing the implausibility argument}

Despite the ever-growing body of evidence in fundamental research on homeopathic preparations (ultra-high dilutions) the issue of implausibility remains due to the lack of a clear mechanism of action.

Sandra Würtenberger (Germany) addressed this issue, presenting the results of a systematic review of physicochemical studies of homeopathic potencies. $72 \%$ of the included studies detected a difference between control and remedy, or between different potencies. The review also identified which physicochemical methods were the most promising. Dr Alexander Tournier (Germany) asked the question of whether homeopathy really is that implausible, by looking in detail at the physics behind current theories of homeopathy's mechanism of action.

These overviews were supported by a number of presentations of original laboratory studies showing clear differences between ultra-high dilutions and controls using a wide range of experimental systems. Presentations given included the effects of Echinacea angustifolia and Thuja occidentalis on cervical cancer cells (Aguilar-Velazquez, Mexico), Phosphorus on macrophages (Bonamin, Brazil) and the anti-mutagenic effects of a combination remedy in vitro (Laurant, France $)^{9}$; potency interactions with solvatochromic dyes (Cartwright, UK) ${ }^{10}$; and plant models such as the effects of various homeopathic 30x preparations on germinating cress seedlings (Sokol, Germany), the reproducibility of Arsenicum album acting on duckweed growth rates (Ücker, Germany) and field-like effects of Arsenicum album 45x on water and/or wheat seeds (Kokornaczyk, Switzerland).

Finally, Dr Michel van Wassenhoven (Belgium) presented the DynHom project which seeks to systematically address the question of the nature of homeopathic preparations by testing two remedies (Cuprum met. and Gelsemium) at different potencies using a host of different physicochemical techniques, including trace analysis techniques to investigate the presence of nanoparticles.

\section{Provings}

The clinical application of homeopathy is fundamentally reliant on reliable proving data, and as such, this area deserves significant research attention. Prof Ashley Ross (South Africa) tackled the fundamental question of whether there is a detectable difference between proving symptoms seen in provers taking placebo, compared with those taking verum; $\mathrm{Dr}$ Robbert van Haselen (France) looked at the validity of proving symptoms when used as statistical predictors of treatment success; and Dr Peter Smith (Germany) presented initial results of a thematic analysis of 17 provings of sarcodes from the domestic pig performed between 1993 and 2017, demonstrating the presence of a consistent core 'picture' across these remedies. 


\section{Qualitative and Veterinary research}

Representing the field of veterinary research, Dr Cidéli Coelho (Brazil) presented the results of her work using potencies of Nux Vomica and Papaver somniferum showing significant shortening of post-operative recovery times of cats following ovariohysterectomy.

Qualitative research aims to document experience and find patterns of meaning in it; $\mathrm{Dr}$ Irene Dorothee Schlingensiepen (Germany) used qualitative research methods to assess the relationship between case-taking/prescribing methods and long-term outcomes for her patients, confirming the importance of finding the "perfect match" remedy for the best clinical outcome. Dr Klaus von Ammon (Switzerland) presented clinical observations made using structured qualitative methods exploring remedy responses that seem compatible with homeopathic medicines having a 'field effect'.

\section{Prognostic factor research}

Prognostic factor research is the systematic study of factors that influence the future outcome of a treatment or disease ${ }^{11}$. In homeopathy research this has been done using Bayes' theorem to assess the likelihood of a relationship between a symptom, remedy and clinical outcome. This new approach was highlighted by two presentations in Malta. Firstly, Dr Robbert van Haselen presented work on prognostic factor research in provings assessing how likely a documented symptom is due to the remedy being proved (see Provings above). Secondly, in clinical treatment, Dr Lex Rutten (Netherlands) presented work on prognostic factor research on homeopathic symptoms in the treatment of cough ${ }^{12}$.

\section{Research priorities for the future}

The second panel discussion - "Research priorities for the future" - opened with a short presentation from Hazel Partington and Dr Jean Duckworth (UK) who described preliminary results from their Delphi study on this topic. Their study showed that overview research was deemed to have had the most impact to date; the most important audiences to reach are policy and decision makers, and the consensus was weighted towards clinical research being a top priority for future research.

Following on from this introduction, each panelist (Dr Stephan Baumgartner, Dr Robbert van Haselen, Dr Elizabeth Thompson and Dr Alexander Tournier) gave a brief summary of what they felt were the priorities for future research before inviting delegates to contribute. The ensuing discussion covered the need for mixed portfolios of evidence, the advantages of pragmatic trials and cohort studies, focusing on 'effectiveness gap' conditions, considering how clinicians use evidence and a reminder that priorities may be different in countries where attitudes to homeopathy are different.

\section{Investing in the future of homeopathy research}

Certain aspects of the Malta Conference were designed specifically to help the Institute fulfil its aim of fostering new high quality research in homeopathy. Firstly, the pre-conference workshop entitled "Making studies count - avoiding common pitfalls in homeopathy research" highlighted ways in which the research community can collaborate to ensure that new studies are in the best strategic direction, take the latest knowledge into consideration and do not repeat old mistakes. Following presentations from Dr Robert Mathie and Dr 
Stephan Baumgartner, workshop attendees were encouraged to examine and discuss practical aspects which should be considered when building trials and experiments.

In addition, HRI was delighted to award HRI Educational Grants to 15 UK-resident homeopaths and researchers, supporting conference attendance. This direct financial support gave the next generation of homeopathy researchers the opportunity to sample the best research currently available, as well as supporting established researchers in disseminating their findings.

\section{Conclusion}

Looking back, HRI Barcelona 2013 was a unique challenge insofar as people told us that it would not be possible to hold a conference dedicated solely to homeopathy research; thanks to the support of our colleagues we were delighted that our inaugural conference was in fact a success. This was followed by Rome 2015 , which came at a time of controversy with publication of the damming Australian report ${ }^{13}$, the effects of which are still being felt worldwide, two years later. Against this backdrop it was rewarding to hear so many people saying that HRI Malta 2017 was our best conference yet. But seeing the conference close with a spontaneous standing ovation was totally unexpected and incredibly moving.

We are proud of the work that the HRI conference team put into Malta and inspired by our colleagues around the world who continue their research undeterred by external pressures. Despite obstacles that at times can seem overwhelming, HRI conferences demonstrate the clear commitment of the homeopathy research community to move forward confidently, striving to improve our skills and generating data of ever-higher quality.

With the resounding success of HRI Malta 2017 still fresh in our minds, plans are already underway to bring you another instalment of Cutting Edge Research in Homeopathy. We look forward to inviting friends, old and new, to join us for HRI London 2019.

Full details of HRI Malta 2017 can be found on the microsite, www.hrimalta2017.org. Information about HRI London 2019 is available on the organisation's website, www.hriresearch.org.

\section{References}

1. Frass $\mathrm{M}$, Friehs $\mathrm{H}$, Thallinger $\mathrm{C}$, et al. Influence of adjunctive classical homeopathy on global health status and subjective wellbeing in cancer patients - A pragmatic randomized controlled trial. Complement Ther Med 2015; 23: 309-317

2. Macías-Cortés E, Llanes-González L, Aguilar-Faisal L, Asbun-Bojalil J. Individualized homeopathic treatment and fluoxetine for moderate to severe depression in peri- and postmenopausal women (HOMDEP-MENOP study): a randomized, double-dummy, doubleblind, placebo-controlled trial. PLoS One 2015; 10: e0118440

3. World Health Organisation (WHO). Global action plan on antimicrobial resistance. http://www.who.int/antimicrobial-resistance/global-action-plan/en/ [Accessed $6^{\text {th }}$ September 2017]

4. Mathie RT, Ramparsad N, Legg LA, et al. Randomised, double-blind, placebo-controlled trials of non-individualised homeopathic treatment: systematic review and meta-analysis. Syst Rev 2017; 6: 63 
5. Homeopathy Research Institute (HRI). The Australian Report. https://www.hriresearch.org/resources/homeopathy-the-debate/the-australian-report-on-homeopathy/ [Accessed 18 ${ }^{\text {th }}$ August 2017]

6. To KLA, Fok YYY, Chong KCM, Lee YCJ, Yiu LSS. Individualized homeopathic treatment in addition to conventional treatment in type II diabetic patients in Hong Kong - a retrospective cohort study. Homeopathy 2017; 106: 79-86

7. Walach H, Köster H, Hennig T, Haag G. The effects of homeopathic belladonna $30 \mathrm{CH}$ in healthy volunteers -- a randomized, double-blind experiment. J Psychosom Res 2001; 50: $155-160$

8. Walach H. Magic of signs: a non-local interpretation of homeopathy. Br Homeopath $J$ 2000; 89: 127-140

9. Di Giorgio C, Boyer L, De Meo M, Laurant C, Elias R, Ollivier E. In vitro and in vivo antimutagenic effects of DIG, a herbal preparation of Berberis vulgaris, Taraxacum officinale and Arctium lappa, against mitomycin C. J Nat Med 2015; 69: 267-277

10. Cartwright SJ. Interaction of homeopathic potencies with the water soluble solvatochromic dye bis-dimethylaminofuchsone. Part 1: pH studies. Homeopathy 2017; 106: $37-46$

11. Riley RD, Hayden JA, Steyerberg EW, et al. Prognosis Research Strategy (PROGRESS) 2: Prognostic Factor Research. PLoS Med 2013; 10: e1001380.

12. Miglani A, Rutten L, Manchanda RK. Generalisability of prognostic factor research: further analysis of data from the IIPCOS2 study. Homeopathy 2017; 106: 155-159

13. National Health and Medical Research Council (NHMRC). Report on Homeopathy. Available from: https://www.nhmrc.gov.au/health-topics/complementarymedicines/homeopathy-review [Accessed $6^{\text {th }}$ September 2017] 